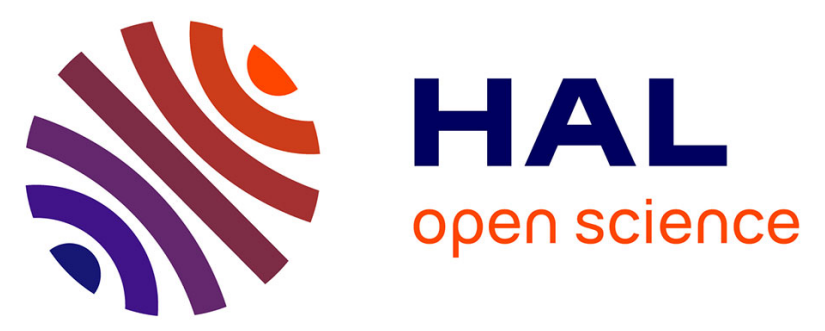

\title{
Formulation of Relationship Between Productivity and Energy Consumption in Manufacturing System
}

\author{
Takayuki Kobayashi, Makoto Yamaguchi, Hironori Hibino
}

\section{To cite this version:}

Takayuki Kobayashi, Makoto Yamaguchi, Hironori Hibino. Formulation of Relationship Between Productivity and Energy Consumption in Manufacturing System. IFIP International Conference on Advances in Production Management Systems (APMS), Sep 2015, Tokyo, Japan. pp.730-737, 10.1007/978-3-319-22756-6_89. hal-01417641

\section{HAL Id: hal-01417641 \\ https://hal.science/hal-01417641}

Submitted on 15 Dec 2016

HAL is a multi-disciplinary open access archive for the deposit and dissemination of scientific research documents, whether they are published or not. The documents may come from teaching and research institutions in France or abroad, or from public or private research centers.
L'archive ouverte pluridisciplinaire HAL, est destinée au dépôt et à la diffusion de documents scientifiques de niveau recherche, publiés ou non, émanant des établissements d'enseignement et de recherche français ou étrangers, des laboratoires publics ou privés. 


\title{
Formulation of relationship between productivity and energy consumption in manufacturing system
}

\author{
Takayuki Kobayashi ${ }^{1}$, Makoto Yamaguchi ${ }^{2}$, and Hironori Hibino ${ }^{1}$ \\ ${ }^{1}$ Tokyo University of Science, 2641 Yamazaki, Noda, Chiba, Japan \\ j7411048@ed.tus.ac.jp \\ ${ }^{2}$ Akita University, 1-1 Tegatagakuen-machi, Akita City, Akita, Japan
}

\begin{abstract}
In the industrial world, since the amount of energy to consume is very large, it is required to manage and reduce energy consumption while maintaining a high productivity. In order to approach the theoretical realization the production conditions that affect a productivity or energy consumption, we investigate the formulation of the relationship between energy consumption and production throughput, and verify it by using numerical simulation.
\end{abstract}

Keywords: Sustainable Manufacturing System, Simulation, Productivity, Energy Consumption, Mathematical Formulation.

\section{Introduction}

Recently, in various fields, reduction of energy consumption has been an important issue.[1,2,3] In particular, in the world of industrial, since the amount of energy to consume is very large, management of energy consumed is greatly required. It is necessary to reduce energy consumption while maintaining a high productivity.[3]

In the previous study, a simulation environment for sustainable manufacturing systems considering the productivity and energy consumption have been established, and an implementation for the simulation environment has been proposed $[5,6]$. The state transition model for facility has been proposed and expressed by using a Unified Modelling Language (UML) model. A case study for a middle-scale semiconductor manufacturing line was carried out by using constructed simulation system. It has been found that the energy consumption per production throughput increase with decreasing lot size and, become a constant value with increasing lot size. This result has indicated that the number of times of setting-up increase with decreasing lot size. Since the energy is required for setting-up, energy consumption per production throughput becomes large.

However, in the manufacturing system, the theoretical realization the production conditions, such as lot size, failure rate, and so on that affect a productivity and energy consumption is not understood clearly. In this paper, therefore, we propose the formulation of the relationship between energy consumption and production through-

adfa, p. 1, 2011.

(C) Springer-Verlag Berlin Heidelberg 2011 
put, and verify it by using numerical simulation system constructed in our previous report.

\section{Formalizing the energy consumption and throughput}

\subsection{Energy consumption per throughput, $U$}

One of the most important indicators in the evaluation of productivity and energy consumption of manufacturing systems is energy consumption per production throughput $(U) . U$ is defined as

$$
U=\frac{E}{P}
$$

Here, $U$ is energy consumption per production throughput and the unit is [ $\mathrm{J} /$ product], $E$ is energy consumption and and the unit is $[\mathrm{J}], P$ is production throughput and the unit is [product]. An electric energy consumption per second is also defined electric power consumption $e[\mathrm{~W}]$.

A line with $n$ equipment which have $m$ kinds of facility state is assumed in this study. An facility in line always belongs to some status during operating time $(T)$, so the operating time of $\mathrm{k}$-th facility $\left(T^{k}\right)$ equal to $T$. The relation between $T$ and the total of operating time of $x$ state in $\mathrm{k}$-th facility $\left(T_{x}^{k}\right)$ is given by

$$
T=T^{k}=\sum_{x}^{m} T_{x}^{k}
$$

The total electric energy consumption is given by

$$
E=\sum_{k}^{n} E^{k}=\sum_{k}^{n} \sum_{x}^{m} e_{x}^{k} T_{x}^{k},
$$

where $E^{k}$ is the total electric energy consumption of k-th facility, and $e_{x}^{k}$ is electric power consumption of $x$ state in k-th facility. Therefore, the energy consumption per production throughput can be written as

$$
U=\sum_{k}^{n} U^{k}=\sum_{k}^{n} \frac{E^{k}}{P}=\sum_{k}^{n} \sum_{x}^{m} \frac{e_{x}^{k} T_{x}^{k}}{P} .
$$

Here $U^{k}$ is the energy consumption per production throughput in k-th facility. By using eq.(4), $U$ can be calculated by $e_{x}^{k}, T_{x}^{k}$ and $P$. Figure 1 shows the summary of the relationship between $E, P, T, U, e$, and $p$. 


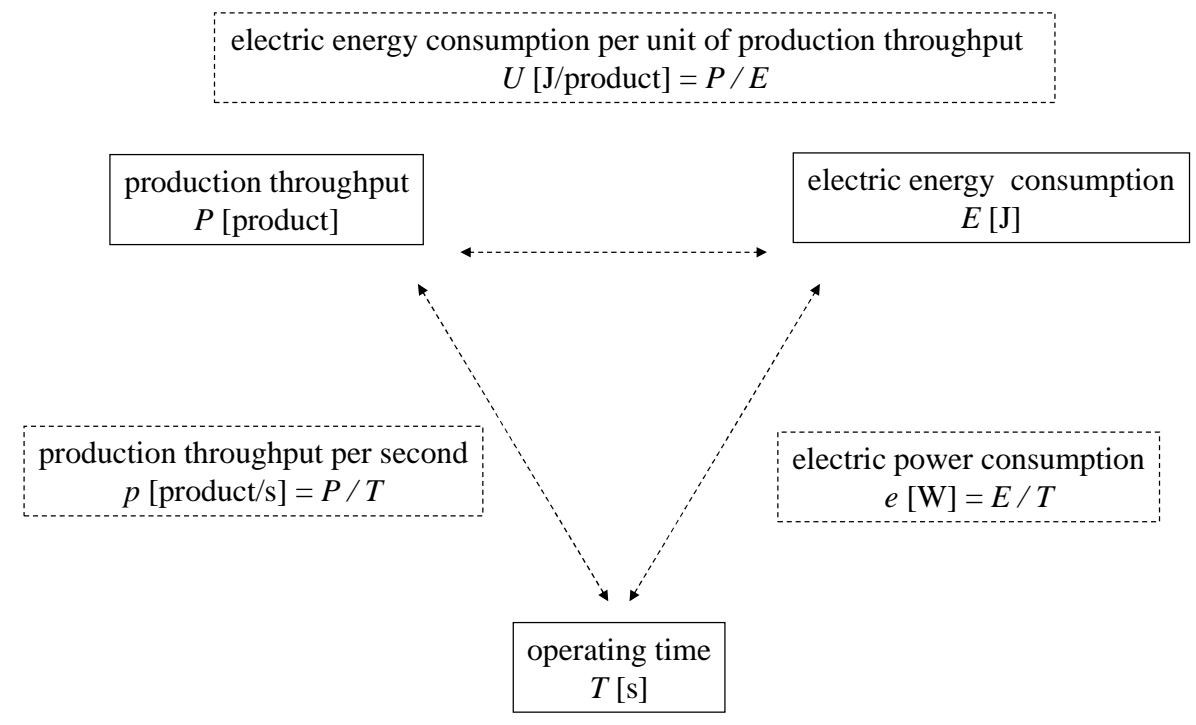

Fig. 1. Relationship between $E, P, T, U, e$, and $p$.

\subsection{Coefficient of work in process, $q^{k}$}

In a line, a buffer is generally set up between facility. When some work exist in a buffer, production throughput in line and production throughput of each facility $\left(P^{k}\right)$ is not same, that is,

$$
P^{k}>P
$$

Here, coefficient of work in process $\left(q^{k}\right)$ can be defined as

$$
q^{k} \equiv \frac{P^{k}}{P}
$$

In the case of $P^{k}=P, q^{k}$ equal 1. Usually, $q^{k}$ increases as previous process, i.e.,

$$
q^{1} \geq \cdots \geq q^{k-1} \geq q^{k} \geq q^{k+1} \geq \cdots \geq q^{n}=1 .
$$

\subsection{Operating time of state of $x$ in k-th facility, $T_{x}^{k}$}

In this study, a state of running, setting-up, and idling will be discussed. The state of running, setting-up, and idling are described by $\mathrm{x}=\mathrm{r}, \mathrm{s}$, and $\mathrm{i}$, respectively.

In a running state in k-th facility, the production throughput per second $\left(p_{r}^{k}\right)$ is the reciprocal of the cycle time $\left(c_{r}^{k}\right)$. Production throughput in k-th facility $\left(P_{r}^{k}\right)$ is calculated by multiplying $T_{r}^{k}$ by $c_{r}^{\mathrm{k}}=1 / p_{r}^{k}$. When the $q_{r}^{k}$ is taken into account, $T_{r}^{k}$ is obtained as

$$
T_{r}^{k}=q^{k} \frac{P}{p_{r}^{k}}
$$


$P$ divided by lot size (LS) is frequency of setting-up in k-th facility. The $q_{r}^{k}$ and $\lambda^{\mathrm{k}}$ which is defended by the time required for a once setting-up are take into consideration, $T_{s}^{k}$ obtained as

$$
T_{S}^{k}=q^{k} \frac{P}{L S} \lambda^{k}
$$

It seems to be reasonable that $T_{s}^{k}$ decrease with increasing LS.

Since a facility in line always belongs to some status during operation, so the operating time of k-th facility $\left(T^{k}\right)$ equal to the sum of $T_{r}^{k}, T_{s}^{k}$ and the operating time of idling state in k-th facility $\left(T_{i}^{k}\right)$;

As $T^{k}=T$,

$$
T^{k}=T_{r}^{k}+T_{s}^{k}+T_{i}^{k}
$$

$$
\begin{aligned}
T_{i}^{k} & =T-T_{r}^{k}-T_{s}^{k} \\
& =T-\frac{q^{k}}{p_{r}^{k}} P-\frac{q^{k} \lambda^{k}}{L S} P \\
& =P\left(\frac{T}{P}-\frac{q^{k}}{p_{r}^{k}}-\frac{q^{k} \lambda^{k}}{L S}\right) \\
& =P\left(\frac{T}{p}-\frac{q^{k}}{p_{r}^{k}}-\frac{q^{k} \lambda^{k}}{L S}\right) .
\end{aligned}
$$

$\mathrm{Eq}(9) \mathrm{eq}(10)$ and eq(11) are substituted into eq(4), $U^{\mathrm{k}}$ is calculated as

$$
\begin{aligned}
U^{k} & =\frac{1}{P}\left(e_{r}^{k} T_{r}^{k}+e_{s}^{k} T_{s}^{k}+e_{i}^{k} T_{i}^{k}\right) \\
& =\frac{1}{P}\left(e_{r}^{k} \frac{q^{k} P}{p_{r}^{k}}+e_{s}^{k} \frac{q^{k} P}{p_{r}^{k}}+e_{i}^{k} P\left(\frac{T}{p}-\frac{q^{k}}{p_{r}^{k}}-\frac{q^{k} \lambda^{k}}{L S}\right)\right) \\
& =q^{k}\left(\frac{e_{r}^{k}}{p_{r}^{k}}+\frac{e_{s}^{k} \lambda^{k}}{L S}\right)+e_{i}^{k}\left(\frac{1}{p}-q^{k}\left(\frac{1}{p_{r}^{k}}+\frac{\lambda^{k}}{L S}\right)\right) .
\end{aligned}
$$

\section{Simulation}

The simulation system of manufacturing has already been developed using the Witness software which is a commercial discrete event simulator (Lanner). In this paper, a middle-scale semiconductor manufacturing line which consist of three facilities, the solder printing facility, the IC mounting facility (mounter facility), and the solder reflow facility is simulated. The three facilities were modelled in Witness using our proposed state transition model. The printing facility, the mounter facility, and the reflow facility are numbered to $\mathrm{k}=1$ to 3 , respectively. Figure 2 show a simulation model of the middle-scale semiconductor manufacturing line. Table 1 shows the simulation input data. In contrast to simulation, input electric power consumption of running state and idle state in reflow facility $\left(e_{r}^{k}\right.$ and $\left.e_{r}^{k}\right)$ different between rising and falling of temperature in furnace, the average value is used in formulation as below. There are four types of lot sizes as $15,30,90,360$. The size of buffer between each facilities is big enough. The simulation period in this simulation is 40 hours ( 5 day $\times$ 8 hours). 


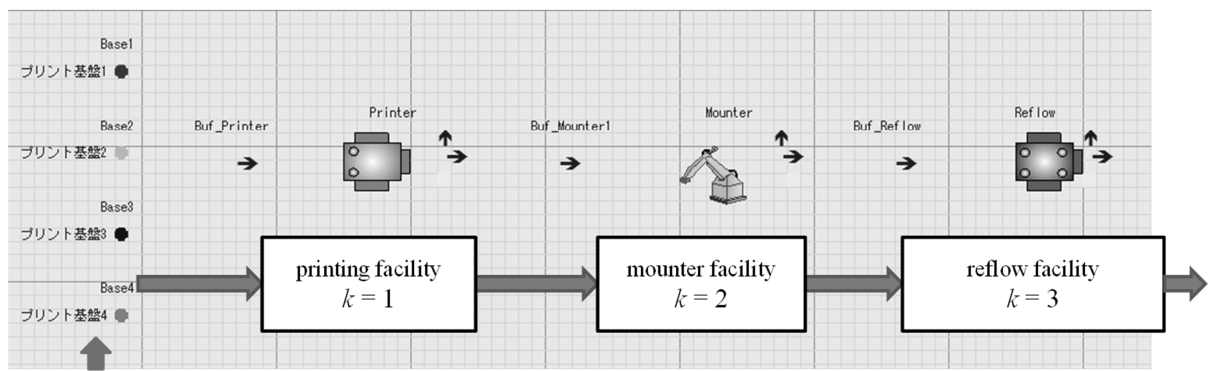

Fig. 2. Simulation model of the middle-scale semiconductor manufacturing line.

Table 1. Input data in simulation.

\begin{tabular}{cccccc}
\hline \multirow{2}{*}{ input data } & & \multicolumn{4}{c}{ Facility } \\
\cline { 3 - 5 } & & $\begin{array}{c}\text { printing } \\
k=1\end{array}$ & $\begin{array}{c}\text { mounter } \\
k=2\end{array}$ & $\begin{array}{c}\text { reflow } \\
k=3\end{array}$ & \\
\hline $1 / p_{r}^{k}$ & {$[\mathrm{~s}]$} & 10 & 10 & 10 & $* 2$ (rising), \\
$e_{r}^{k}$ & {$[\mathrm{~kW}]$} & 1.25 & 3.75 & $0.8^{*}$ & 1.2 (falling) \\
$\lambda^{k}$ & {$[\mathrm{~s}]$} & 120 & 120 & - & \\
$e_{s}^{k}$ & {$[\mathrm{~kW}]$} & 3 & 1.5 & - & $* 0.4$ (rising), \\
$e_{i}^{k}$ & {$[\mathrm{~kW}]$} & 0.2 & 0.2 & $0.8^{*}$ & 1.2 (falling) \\
\hline
\end{tabular}

\section{$4 \quad$ Results and Discussion}

Figure 3 show the relationship between electric energy consumption per production throughput and inverse of lot size. The opened circle in Fig. 3 indicate the simulation results of the electric energy consumption per production throughput of printing facility $\left(U^{1}\right)$. Note that the linear correlation exists between the $U^{1}$ and inverse of lot size. In this simulation, since the cycle time of facilities is almost same, and the failure of facilities is not considered, the $q^{k}$ can be considered as 1 . Furthermore, the operating time of idling state in the printing facility is zero, because the size of buffer between each facilities is big enough. Taking these assumption into account, $U^{1}$ and $p$ are given by

$$
\begin{aligned}
U^{1} & =\left(\frac{e_{r}^{1}}{p_{r}^{1}}+\frac{e_{s}^{1} \lambda^{1}}{L S}\right), \\
\frac{1}{p} & =\left(\frac{1}{p_{r}^{1}}+\frac{\lambda^{1}}{L S}\right),
\end{aligned}
$$


respectively. The dashed line in Fig. 3 denotes calculated eq. (13). The simulation results and formulation results are in reasonably good agreement. The opened circle and dashed line in Fig.4 indicate the simulation results of production throughput and formulation results (eq.(14)), respectively. Note that the results agrees well. We can obtain a relation between $U^{1}$ and $p$ as

$$
U^{1}=\frac{e_{s}^{1}}{p}+\frac{e_{r}^{1}}{p_{r}^{1}}-\frac{e_{s}^{1}}{p_{r}^{1}}
$$

from Eq. (13) and (14). We can understand that energy consumption per production throughput decreases with an increase productivity.

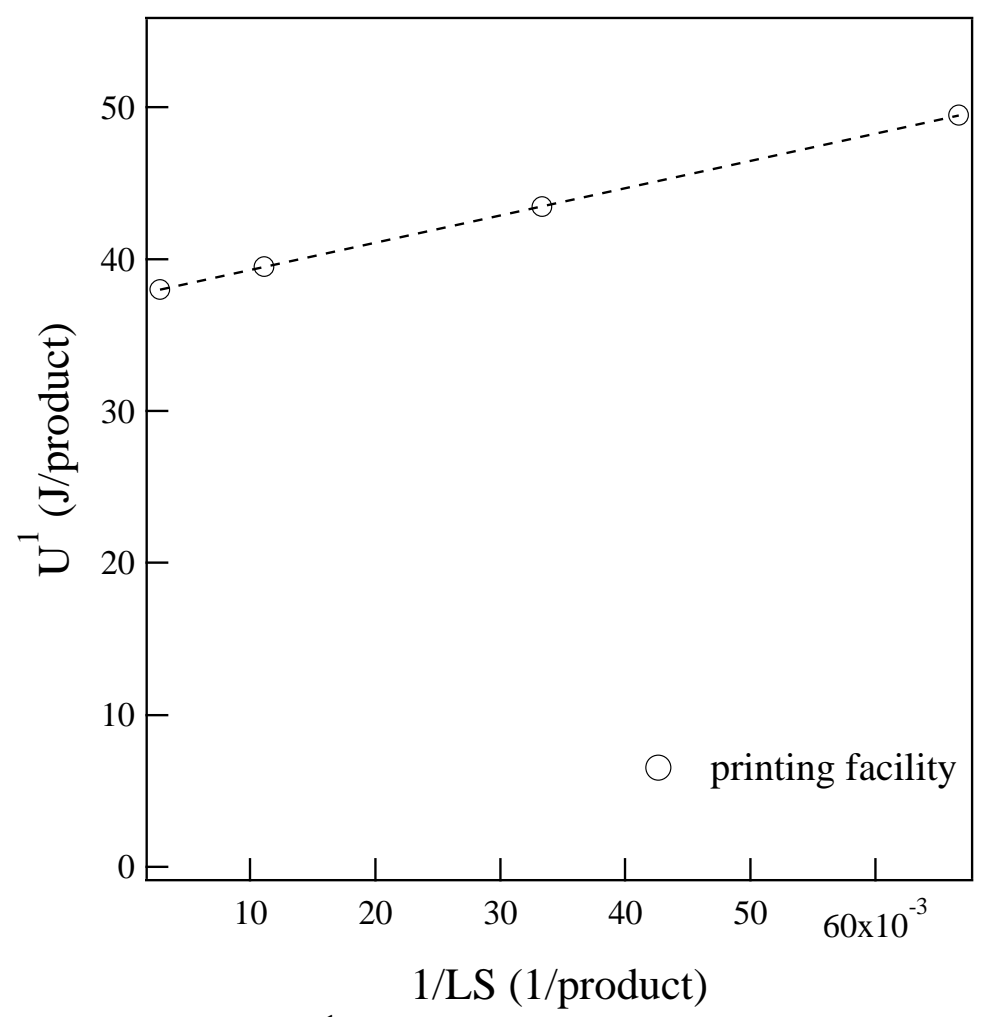

Fig.3. $L S$ dependence of $U^{1}$. Simulation results (open circle) and formulation results (dashed line) 


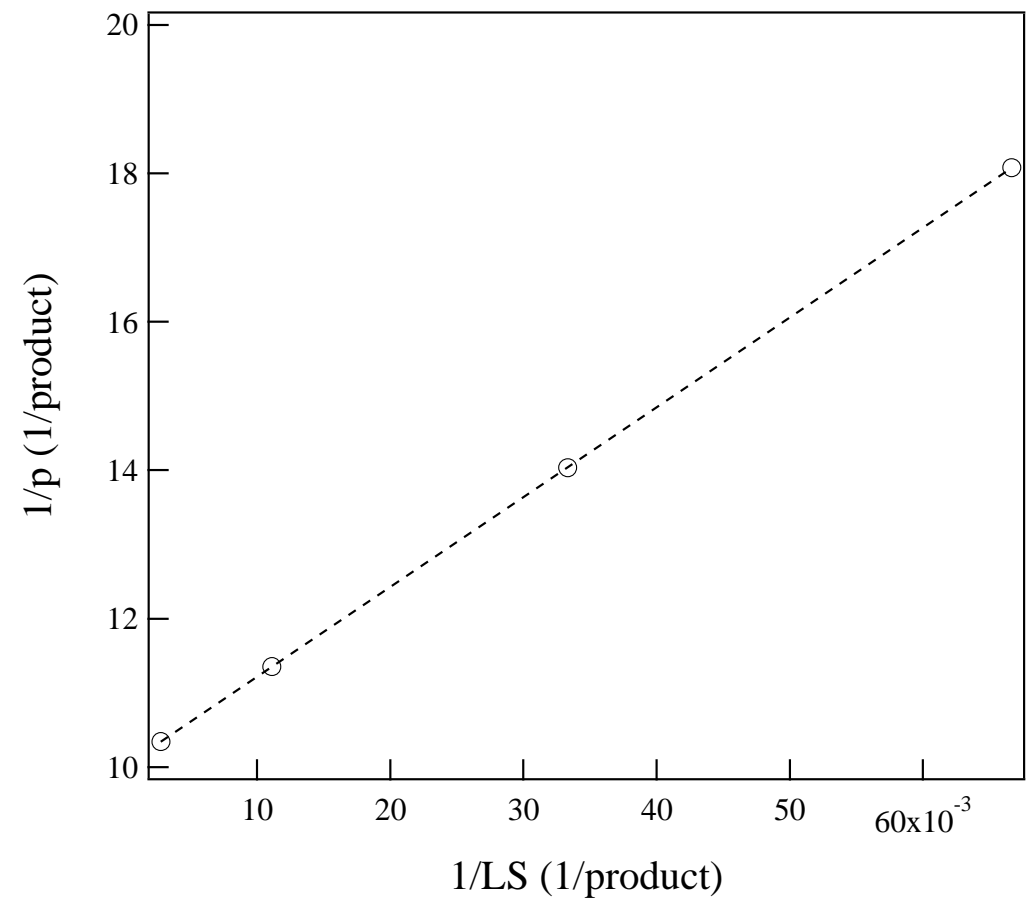

Fig. 4. $L S$ dependence of $1 / p$. Simulation results (open circle) and formulation results (dashed line)

\section{Conclusion}

In order to approach the theoretical realization the production conditions that affect a productivity or energy consumption, we investigated the formulation of the relationship between energy consumption and production throughput, and verified it by using numerical simulation. The simulation results and formulation results are in reasonably good agreement. The relation between lot size and energy consumption per production throughput, production throughput were understood. It is clearly shown that energy consumption per production throughput decreases with an increase productivity.

\section{Reference}

1. Göschel , A., Schieck, F. and Schönherr, J., Method for energy and resource balancing demonstrated as an example of the hot sheet metal production process, CIRP AnnalsManufacturing Technology, Vol. 61, No. 1(2012), pp.399-402.

2. Fujitsu, Co., Green Monodukuri: RAGON,

http://jp.fujitsu.com/about/csr/eco/services/energysaving/emdragon/ (accessed 2012-5-18). 
3. Nissan Motor Co., A case study of energy consumption per unit of production throughput, http://www.jsme.or.jp/publish/ronbun/JSME_Manual_20100730.pdf (accessed 2011-510).

4. The Energy Conservation Center Japan, The revised energy conservation law, http://www.eccj.or.jp/law/pamph/outline_revision/new_outline2010.pdf (accessed 20114-25).

5. Hibino, H., Sakuma, T., Yamaguchi, M. : Manufacturing System Simulation for Evaluation of Productivity and Energy Consumption. Journal of Advanced Mechanical Design, System, and Manufacturing, Vol. 8 (2014) No. 2 , p. 1-13

6. Hibino, H., Sakuma, T., Yamaguchi, M. : Simulation for Sustainable Manufacturing System Considering Productivity and Energy Consumption. Advances in Production Management Systems. Innovative and Knowledge-Based Production Management in a GlobalLocal World, IFIP Advances in Information and Communication Technology. Volume 439, 2014, pp 310-318 